\title{
Prevalence and Incidence of Orofacial Cleft Anomalies in Children with Cleft Lip and Palate Associated with Etiological Deformities in Hail Region, Saudi Arabia
}

\author{
Abdullah Faraj AIShammari ${ }^{1}$, Dalal Habib AIShammary ${ }^{1}$, Hasna Rasheed Alshubrmi ${ }^{1}$, \\ Ebtsam Abdullah Aledaili ${ }^{2}$, Hazza Abdullah Alhobeira ${ }^{1}$, Hussain Gadelkarim Ahmed ${ }^{3, *}$ \\ ${ }^{1}$ College of Dentistry, University of Hail, Kingdom of Saudi Arabia (KSA) \\ ${ }^{2}$ Ministry of Health, University of Hail \\ ${ }^{3}$ College of Medicine, University of Hail \\ *Corresponding author: hussaingad1972@yahoo.com
}

\begin{abstract}
Aim: The aim of this study was to explore the prevalence, incidence and possible etiological risk factors of orofacial cleft in Hail Region, Northern Saudi Arabia. Methodology: This is a retrospective study conducted in Maternity Hospital, Hail, Saudi Arabia. Data of seven years (2011-2017) records of newborn infants were reviewed for the presence of orofacial anomalies (included 27800 files). Results: The overall prevalence rate of orofacial cleft was 1.08 per 1000 births. Out of 30 patients diagnosed with orofacial anomalies, 14(46.7\%) were found with cleft palate, 11(36.7\%) with bilateral cleft lip and palate, 4(13.3\%) with bilateral cleft lip and only one (3.3\%) with unilateral cleft lip and palate. Conclusion: The prevalence of orofacial clefts in Northern Saudi Arabia was similar or slightly lower than the higher global reported rates. Cleft palate was the most common type of orofacial cleft in Northern Saudi Arabia.
\end{abstract}

Keywords: orofacial cleft, cleft palate, cleft lip, orofacial anomalies, Saudi Arabia

Cite This Article: Abdullah Faraj AlShammari, Dalal Habib AlShammary, Hasna Rasheed Alshubrmi, Ebtsam Abdullah Aledaili, Hazza Abdullah Alhobeira, and Hussain Gadelkarim Ahmed, "Prevalence and Incidence of Orofacial Cleft Anomalies in Children with Cleft Lip and Palate Associated with Etiological Deformities in Hail Region, Saudi Arabia.” International Journal of Dental Sciences and Research, vol. 5, no. 6 (2017): 141-145. doi: 10.12691/ijdsr-5-6-2.

\section{Introduction}

Orofacial cleft includes cleft lip and cleft palate, is a group of anomalies, which includes cleft lip (CL), cleft palate (CP), and both together (CLP) [1]. Cleft lip and cleft palate are birth defects that occur when an infant's lip or mouth don't form properly during pregnancy. Newborn with orofacial anomaly can has a cleft lip, a cleft palate or both [2]. Orofacial clefting could significantly affect the quality of life of the child and needs various steps of care to achieve the best outcome [3].

Orofacial clefts are one of the most common birth defects in humans with a prevalence of 1: 700 . Non-syndromic cleft lip with or without cleft palate or isolated cleft palate display a partial separation of the oral cavity and the nasal space without any extra malformations. Beside complete cleft palate also sub-mucous cleft palates occur that are concealed underneath the intact mucosa [4]. Centers for Disease Control and Prevention (CDC) has estimated that, each year in the United States, about 2,650 babies are born with a cleft palate and 4,440 babies are born with a cleft lip with or without a cleft palate [5]. Isolated orofacial clefts, or clefts that occur with no other major birth defects, are one of the most common types of birth defects in the United States [5]. Depending on the cleft type, the rate of isolated orofacial clefts can vary from $50 \%$ to $80 \%[6,7,8]$.

The etiology of clefts is a multifarious interaction between environmental and genetic factors [4]. Based on epidemiological and embryological data, cleft lip and/or palate and cleft palate are considered distinct forms of orofacial clefting [9]. Food intake, metabolic, hormonal, lifestyle, and genetic factors determine the nutritional status of the mother and could thereby affect organogenesis and growth of the conceptus [10]. Derangements in these molecular processes caused by polymorphisms in developmental genes and/or environmental exposures are proposed to cause orofacial clefts [11].

Many maternal exposures during first trimester have been described to be connected with orofacial cleft, comprising use of anticonvulsants or retinoids [12], hazardous habits such as smoking $[13,14]$ and regular alcohol intake [15], residential proximity to sites of increased chemical pollution [16], consumption of supplementation, and firsttrimester fever-producing illnesses including influenza [17].

Orofacial cleft conditions were not assessed before in Hail Region, therefore, this hospital-based case-control study was performed to explore the prevalence, incidence and possible etiological risk factors of orofacial cleft in Hail Region, Northern Saudi Arabia. 


\section{Materials and Methods}

This is a retrospective study conducted in Maternity Hospital, Hail, Saudi Arabia. Data of seven years records of newborn infants were reviewed for the presence of orofacial anomalies (included 27800 files). Thirty patients were categorized as having orofacial anomalies and were further ascertained as study subjects (cases). Records of 26 newborn infants from the same years were further included to serve as control for the assessment of etiological factors. All Records regarding study subjects were retrieved from newborn infants' files in Hail's Maternity Hospital including years from 2011 to 2017. Furthermore, the parents of the selected study subjects were contacted and interviewed to fulfillment the required information in the questionnaire, which included: sex, age, nationality, diagnosis of orofacial anomalies, gestational period, type of marriage, drug usage during pregnancy, history of cigarette smoking, history of mother's exposure to chemicals or viral infection, history of alcohol abuse, history of folic acid deficiency, and history of vitamins deficiency.

Statistical analysis: Data management was done using Statistical Package for Social Sciences (SPSS version 16). SPSS was used for analysis and to perform Pearson Chi-square test for statistical significant $(\mathrm{P}$ value $\mathrm{P}<0.5)$. The $95 \%$ confidence level and confidence intervals were used.

\section{Results}

This study investigated data recorded for 56 newborn infants, of whom 30 were infants with orofacial clefts (cases) and the remaining 26 newborn infants were used as control group. Of the 30 cases collected from 7 years records, the majority of cases were recorded in the year 2012 followed by 2013, and 2014, constituting 9/30(30\%),
7/30(23.3\%) and 5/30(16.7\%), respectively, as shown in Table 1 . Figure 1 . The prevalence rate of orofacial cleft was 1.08 per 1000 births. The incidence rates in the 7 years was shown in Table 1.

Table 1. Study population in 7 years

\begin{tabular}{ccccc}
\hline Variable & Cases & Controls & Total & Incidence \\
\hline 2011 & 3 & 0 & 3 & $0.07 \%$ (0.7 per 1000 birth $)$ \\
2012 & 9 & 0 & 9 & $0.21 \%$ ( 2.1 per 1000 birth) \\
2013 & 7 & 7 & 14 & $0.16 \%(1.6$ per 1000 birth) \\
2014 & 5 & 0 & 5 & $0.12 \%(1.2$ per 1000 birth $)$ \\
2015 & 3 & 7 & 10 & $0.07 \%$ (0.7 per 1000 birth) \\
2016 & 2 & 11 & 13 & $0.05 \%(0.5$ per 1000 birth) \\
2017 & 1 & 1 & 2 & $0.02 \%(0.2$ per 1000 birth) \\
Total & 30 & 26 & 56 & \\
\hline
\end{tabular}

Table 2. Distribution of sex by diagnosis, gestational period and type of marriage

\begin{tabular}{|lcccc|}
\hline variable & Males & Females & Total & Prevalence \\
Diagnosis & & & & Per 1000 \\
Unilateral cleft lip and palate & 1 & 0 & 1 & 0.035 \\
Bilateral cleft lip and palate & 3 & 8 & 11 & 0.39 \\
Bilateral cleft lip & 2 & 2 & 4 & 0.14 \\
Cleft palate & 6 & 8 & 14 & 0.5 \\
Total & 12 & 18 & 30 & 1.08 \\
Gestational period & & & & \\
35 weeks & 0 & 3 & 3 & \\
36 weeks & 12 & 15 & 27 & \\
Total & 12 & 18 & 30 & \\
Type of marriage & & & & \\
consanguineous & 12 & 18 & & \\
Non- consanguineous & 0 & 0 & & \\
\hline
\end{tabular}

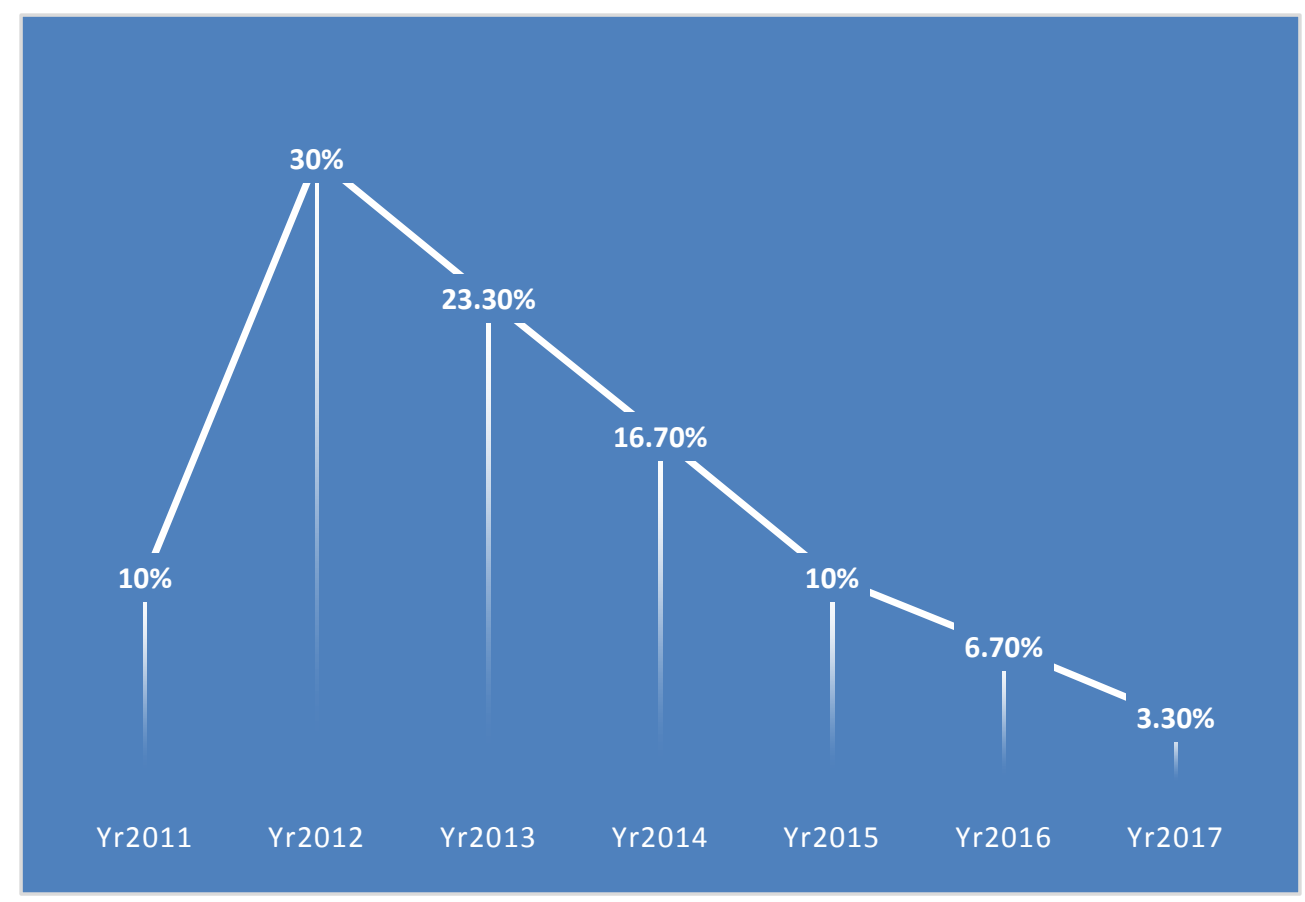

Figure 1. Proportions of the Study population in 7 years 


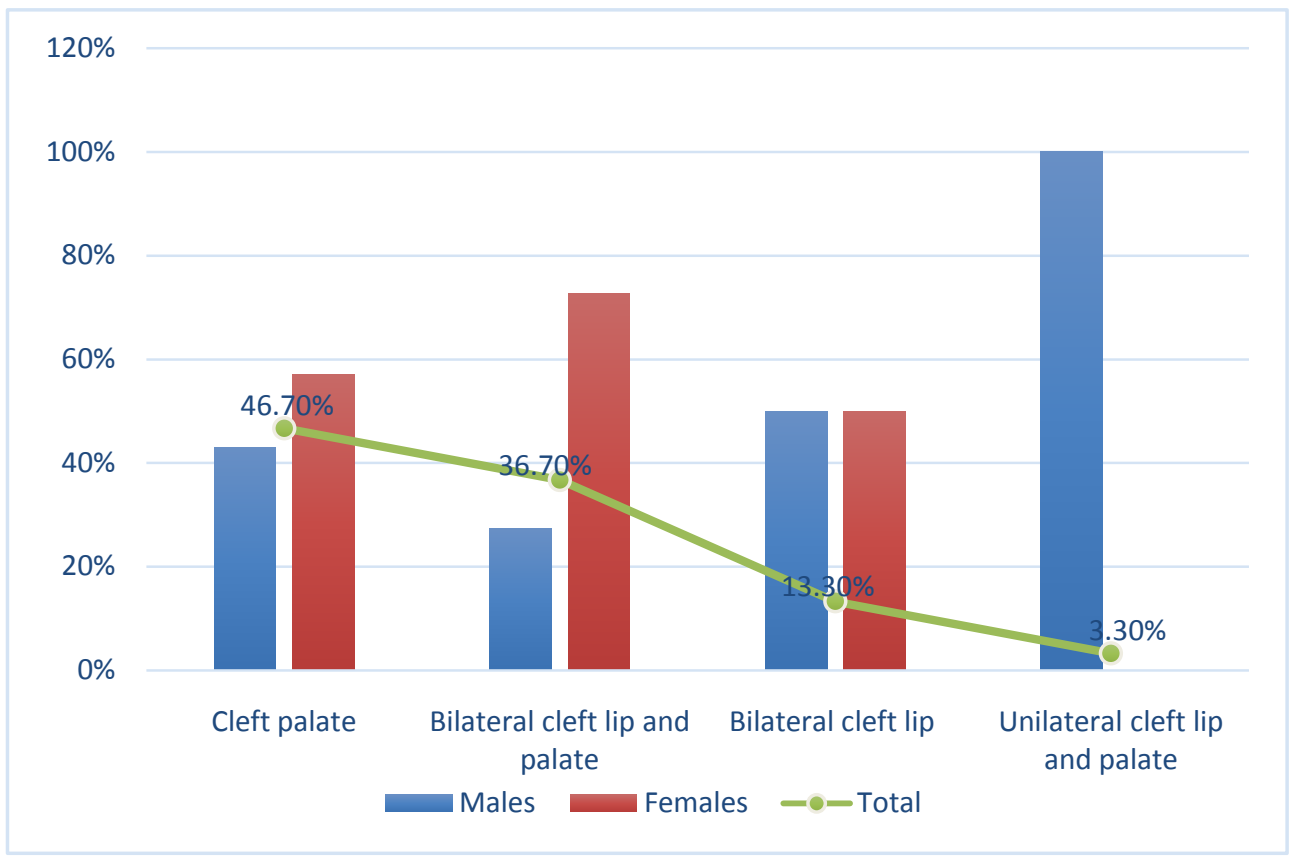

Figure 2. Description of sex by diagnosis

Regarding diagnosis, out of the 30 patients diagnosed with orofacial anomalies, 14(46.7\%) were found with cleft palate, 11(36.7\%) with bilateral cleft and palate, 4(13.3\%) with bilateral cleft lip and only one (3.3\%) with unilateral cleft lip and palate. Of the 14 patients with cleft palate, 6/14(43\%) were males and 8/14(57\%) were females. Of the 11 patients with Bilateral cleft lip and palate, $3 / 11(27.3 \%)$ were males and $8 / 11(72.7 \%)$ were females. Of the 4 patients with Bilateral cleft lip, 2/4(50\%) were males and 2/4(50\%) were females. The only one patient with unilateral cleft lip and palate was male, as shown in Figure 2.

The gestational period was 36 weeks for $27(90 \%)$ of the cases and 35 weeks for $3(10 \%)$ of the cases.

With regard to the marriage type, all cases (100\%) were found among consanguineous type of marriage.

Table 3. Distribution of sex by parent age

\begin{tabular}{|l|c|c|c|}
\hline variable & Males & Females & Total \\
Father's age & & & \\
$31-40$ years & 3 & 2 & 5 \\
$41+$ & 5 & 11 & 16 \\
Total & 4 & 5 & 9 \\
Mather's age & 12 & 18 & 30 \\
$<30$ years & 5 & 7 & 12 \\
$31-40$ & 6 & 7 & 13 \\
$41+$ & 1 & 4 & 5 \\
Total & 12 & 18 & 30 \\
\hline
\end{tabular}

For the father's age, most of them were found at age group 31-40 followed by 41+ representing 16(53.3\%) and 9(30\%) respectively. For the Mather's age, most of them were found at age group 31-40 followed by $<30$ representing 13(43.3\%) and 12(40\%) respectively. About $11 / 18(\%)$ of the females infants belong to the fathers who is age at 31-40 years, as indicated in Table 3.
With regard to the distribution of the parents of cases and controls by possible etiological factors, 28 (93.3\%) and $9(34.6 \%)$ of the cases and controls respectively were found smokers. These findings indicate that cigarette smoking is a risk factor for occurrence of orofacial cleft and this was found to be statistically significant ( $P$ $<0.001$ ), as indicated in Table 4 .

Table 4. Distribution of parents of cases and controls by possible etiological factors

\begin{tabular}{lcccc}
\hline Variable & cases & controls & Total & P value \\
\hline Cigarette smoking & & & & 0.0001 \\
Father smokers & 26 & 9 & 35 & \\
Mother smokers & 1 & 0 & 1 & \\
Non-smokers & 3 & 17 & 20 & \\
Total & 30 & 26 & 56 & \\
History of drug use or & & & & 0.100 \\
viral infection & & & & \\
Yes & 3 & 0 & 3 & \\
No & 27 & 26 & 53 & \\
$\begin{array}{l}\text { History of folic acid } \\
\text { deficiency }\end{array}$ & & & & 0.0001 \\
Yes & 22 & 0 & 8 & \\
$\begin{array}{l}\text { No } \\
\text { History of vitamins } \\
\text { deficiency }\end{array}$ & 8 & 26 & 48 & \\
Yes & & & & 0.0001 \\
No & 28 & 4 & 32 & \\
\hline
\end{tabular}

About 3 (10\%) and 3(11.5\%) of the cases and controls respectively were found with a history of drug use or viral infection, as indicated in Table 4.

Around 22 (73.3\%) of the cases were found with a history of folic acid deficiency, but no one in control group. These findings indicate that folic acid deficiency is a risk factor for occurrence of orofacial anomalies and this was found to be statistically significant $(\mathrm{P}<0.001)$, as indicated in Table 4. 
About 28 (93.3\%) and 4(15.4\%) of the cases and controls respectively were found with a history of vitamins deficiency. These findings indicate that vitamins deficiency is a risk factor for occurrence of orofacial cleft and this was found to be statistically significant ( $P$ $<0.001$ ), as indicated in Table 4.

\section{Discussion}

Orofacial cleft is associated with several multifactorial risk factors including genetic and environmental risk factors, which differs according to different demographical factors. Consequently, the epidemiology of orofacial cleft greatly vary. Therefore, the present study assessed the epidemiology of orofacial cleft in Northern Saudi Arabia (Hail Region) for the first time.

In the present study, the prevalence of orofacial cleft was found to be 1.08 per 1000 births. The global average prevalence of all orofacial clefts is 9.92 per 10.000 , but there is substantial variation among different population [18]. The higher birth defect prevalence rates were reported from East Asian and Native American populations followed by European and South Asian populations, while the lower birth defect prevalence rates were reported from African ancestry population [19-21]. In the current study, the incidence rates greatly vary within the different years (ranged from 2.1 per 1000 birth to 0.2 per 1000 birth). These incidence rates were within the relatively average rates, since the reported incidence rates for isolated cleft palate (rare type) were ranging from 0.13 to 2.53 per 1000 live births. The incidence rates of orofacial cleft varies substantially by geography with the lowest rates in Africa and the highest rates in British, Columbia and Canada [22].

A recent study from Saudi Arabia involved the study of orofacial cleft in three cities has reported relatively similar findings. The prevalence of non-syndromic orofacial cleft was higher in Madinah (1.88/1000 births) than in Jeddah (0.81/1000 births), and Riyadh (1.07/1000 births) [23]. In this study, the majority of cases were found with cleft palate, which is relatively similar to the reported values from Saudi Arabia [23].

With regard to the marriage type, all cases (100\%) were found among consanguineous type. There are several studies suggesting that consanguinity is a risk factor for orofacial cleft, particularly from Saudi Arabia [24,25]. Such findings may suggest the role of genetic etiology, which necessitate the need for genetic analysis.

With regard to the association between parent's age and orofacial cleft, most of parents were found at age range 30-40 years and slightly shift to older particularly for fathers. Several studies were conducted for mother's and father's age. The risk increased with the age of both parents, with risk estimates of 1.27 per 1000 and higher for children of parents at an advanced age. In an interaction analysis, the risk was increased only when the age of both parents was high [26].

The findings of the present study indicated that cigarette smoking is a risk factor for occurrence of orofacial cleft and this was found to be statistically significant $(\mathrm{P}<0.001)$. A meta-analysis of the association between maternal smoking during pregnancy and orofacial cleft found a reliable, moderate and statistically significant associations between maternal smoking and cleft lip, with or without cleft palate (relative risk 1.34, 95\% confidence interval 1.25-1.44) and between maternal smoking and cleft palate (relative risk 1.22, 95\% confidence interval 1.10-1.35) [27].

The results of the current study indicated that folic acid deficiency is a risk factor for occurrence of orofacial cleft and this was found to be statistically significant ( $P$ $<0.001)$. Several studies have identified the risk factors like folic acid deficiency during gestational period, family history for orofacial clefts, drugs like antiepileptic, vitamin A [28]. Evidence from several studies showed that mothers who are supplemented with folic acid in their peri-conceptional period and early pregnancy have significantly reduced adverse outcomes like birth defects [29].

Our findings indicated that vitamins deficiency is a risk factor for occurrence of craniofacial anomalies and this was found to be statistically significant $(\mathrm{P}<0.001)$. Periconceptional multivitamin supplementation has been reported to decrease the risk of orofacial clefts in offspring, but high intake of preformed vitamin A (retinol) might be undesirable [30].

The limitation of the presence study was the absence of genetic factors assessment.

\section{Conclusion}

The prevalence of orofacial clefts in Saudi Arabia was similar or slightly lower than the higher global reported rates. Cleft palate was the most common type of orofacial cleft in Northern Saudi Arabia. Etiological factors such as smoking and vitamins deficiencies may strongly contribute to the etiology of orofacial anomalies in Hail Region. Further studies encountering genetic analysis are needed to assist in future prevention program.

\section{Acknowledgements}

Authors would like to thank people at Hail Maternity Hospital for their help in data retrieval. Also our deep thank go to the parent of the children involved in the study.

\section{Ethical Consent}

The protocol of the present study was approved by the ethical committee at College of Medicine, University of Hail. The informed consent was agreed about by Hail Maternity Hospital. All dealings performed in this study were in accordance with the ethical standards of the 1964 Helsinki declaration and its later amendments or comparable ethical standards.

\section{Conflict of Interest}

Authors declare no potential conflict of interest. 


\section{References}

[1] CDC. Facts about Cleft Lip and Cleft Palate 2017. Retrieved 2017. Available at: https: //www.cdc.gov/ncbddd/birthdefects/cleftlip.html.

[2] CDC. Birth defect. Facts about Cleft Lip and Cleft Palate 2017. Retrieved 2017. Available at: https: //web.archive.org/web/20150508162121/http: //www.cdc.gov/ncbddd/birthdefects/CleftLip.html.

[3] Crockett DJ, Goudy SL. Cleft lip and palate. Facial Plast Surg Clin North Am. 2014 Nov; 22(4): 573-86.

[4] Reiter R, Haase S, Brosch S. Orofacial clefts. Laryngorhinootologie 2012; 91(2): 84-95.

[5] Parker SE, Mai CT, Canfield MA, Rickard R, Wang Y, Meyer RE, Anderson P, Mason CA, Collins JS, Kirby RS, Correa A; for the National Birth Defects Prevention Network. Updated national birth prevalence estimates for selected birth defects in the United States, 2004-2006. Birth Defects Research (Part A): Clinical and Molecular Teratology 2010; 88: 1008-16.

[6] Little J, Cardy A, Munger RG. Tobacco smoking and oral clefts: a meta-analysis. Bull World Health Organ. 2004; 82: 213-18.

[7] Honein MA, Rasmussen SA, Reefhuis J, Romitti P, Lammer EJ, Sun L, Correa A. Maternal smoking, environmental tobacco smoke, and the risk of oral clefts. Epidemiology 2007; 18: 226-33.

[8] Yazdy MM, Autry AR, Honein MA, Frias JL. Use of special education services by children with orofacial clefts. Birth Defects Research (Part A): Clinical and Molecular Teratology 2008; 82: $147-54$.

[9] Jiang R, Bush JO, Lidral AC. Development of the upper lip: morphogenetic and molecular mechanisms. Dev Dyn. 2006; 235(5): 1152-66.

[10] Steegers-Theunissen RP, Steegers EA. Nutrient-gene interactions in early pregnancy: a vascular hypothesis. Eur J Obstet Gynecol Reprod Biol. 2003; 106(2): 115-7.

[11] Wyszynski DF, Beaty TH. Review of the role of potential teratogens in the origin of human nonsyndromic oral clefts. Teratology. 1996 May; 53(5): 309-17.

[12] Reefhuis J, de Jong-van den Berg LT, Cornel MC. The use of birth defect registries for etiological research: a review. Community Genet. 2002; 5(1): 13-32.

[13] Krapels IP, Zielhuis GA, Vroom F, et al. Periconceptional health and lifestyle factors of both parents affect the risk of live-born children with orofacial clefts. Birth Defects Res A Clin Mol Teratol. 2006 Aug; 76(8): 613-20.

[14] Shaw GM, Wasserman CR, Lammer EJ, O'Malley CD, Murray JC, Basart AM, Tolarova MM. Orofacial clefts, parental cigarette smoking, and transforming growth factor-alpha gene variants. Am J Hum Genet. 1996 Mar; 58(3): 551-61.

[15] Murray JC. Gene/environment causes of cleft lip and/or palate. Clin Genet. 2002 Apr; 61(4): 248-56.
[16] Brender JD, Zhan FB, Suarez L, Langlois PH, Moody K. Maternal residential proximity to waste sites and industrial facilities and oral clefts in offspring. J Occup Environ Med. 2006 Jun; 48(6): 565-72.

[17] Wang W, Guan P, Xu W, Zhou B. Risk factors for oral clefts: a population-based case-control study in Shenyang, China. Paediatr Perinat Epidemiol. 2009 Jul; 23(4): 310-20.

[18] Watkins SE, Meyer RE, Strauss RP, Aylsworth AS. Classification, epidemiology, and genetics of orofacial clefts. Clin Plast Surg. 2014; 41(2): 149-63.

[19] IPDTOC Working Group: Prevalence at birth of cleft lip with or without cleft palate: data from the International Perinatal Database of Typical Oral Clefts (IPDTOC). Cleft Palate Craniofac J. 2011; 48(1): 66-81.

[20] Allagh KP, Shamanna BR, Murthy GV, et al.. Birth prevalence of neural tube defects and orofacial clefts in India: a systematic review and meta-analysis. PLoS One. 2015; 10(3): e0118961.

[21] Butali A, Adeyemo WL, Mossey PA, et al.: Prevalence of orofacial clefts in Nigeria. Cleft Palate Craniofac J. 2014; 51(3): 320-5.

[22] Burg ML, Chai Y, Yao CA, Magee W, Figueiredo JC. Epidemiology, Etiology, and Treatment of Isolated Cleft Palate. Frontiers in Physiology. 2016; 7: 67.

[23] Sabbagh HJ, Innes NP, Sallout BI, et al. Birth prevalence of nonsyndromic orofacial clefts in Saudi Arabia and the effects of parental consanguinity. Saudi Medical Journal. 2015; 36(9): 1076-1083.

[24] Ravichandran K, Shoukri M, Aljohar A, Shazia NS, Al-Twaijri Y, Al Jarba I. Consanguinity and occurrence of cleft lip/palate: a hospital-based registry study in Riyadh. Am J Med Genet A. 2012; 158A(3): 541-6.

[25] Sabbagh HJ, Hassan MH, Innes NP, Baik AA, Mossey PA. Parental consanguinity and nonsyndromic orofacial clefts in children: a systematic review and meta-analyses. Cleft Palate Craniofac J. 2014; 51(5): 501-13.

[26] Berg E, Lie RT, Sivertsen Å, Haaland ØA. Parental age and the risk of isolated cleft lip: a registry-based study. Ann Epidemiol. 2015; 25(12): 942-7. e1.

[27] Little J, Cardy A, Munger RG. Tobacco smoking and oral clefts: a meta-analysis. Bulletin of the World Health Organization. 2004; 82(3): 213-218.

[28] Brooklyin S, Jana R, Aravinthan S, Adhisivam B, Chand P. Assessment of Folic Acid and DNA Damage in Cleft Lip and Cleft Palate. Clinics and Practice. 2014; 4(1): 608.

[29] Murthy GVS, Kolli SR, Neogi SB, et al. A Mixed-Method Study to Determine the Benefits of Periconceptional Folic Acid Supplementation and Effects of Folic Acid Deficiency in Mothers on Birth Outcomes. Eysenbach G, ed. JMIR Research Protocols. 2016; 5(2): e129.

[30] Hozyasz K, Chełchowska M, Surowiec Z. Plasma vitamin A in mothers of children with orofacial clefts. Ginekol Pol. 2004; 75(2): $139-44$. 